\title{
Research on the general technical standards of the gasoline vapor recovery unit set
}

\author{
Huang Jin, ${ }^{1, *}$, Zhang Bingquan ${ }^{2}$ Huang Weiqiu ${ }^{5}$, Zhu Zhiping ${ }^{3}$, Feng Tao ${ }^{4}$,Wang Quanzhan ${ }^{4}$, Huang Zhaohui ${ }^{6}$, Zhu \\ Jianjun $^{2}$, Zhang Xiaoxin ${ }^{1}$, Zhang Lin $^{3}$ \\ ${ }^{1}$ China National Institute of Standardization, Beijing 100191, China \\ ${ }^{2}$ Jiangsu Aerospace Hewlett Environmental Protection Technology Co., LTD \\ ${ }^{3}$ Nanjing Dole Refrigeration Equipment Co., LTD \\ ${ }^{4}$ China National Petroleum Corporation \\ ${ }^{5}$ ChangZhou University \\ ${ }^{6} \mathrm{JiangSu}$ Institute of Metrology
}

\begin{abstract}
Along with the increasingly strict environmental regulation and the willingness to rapidly promote gasoline vapor recovery management, the development of technology and equipment for gasoline vapor recovery industry grows faster, and the demand for relevant technical standards is also growing. Based on the domestic and foreign development situation of gasoline vapor recovery technology and standard, this article analyzes necessity and urgency of the general technical standards for development of China's vapor recovery unit, and then it introduces the main technical content of the national standard GB/T 35579-2017 General Specifications of Gasoline Vapor Recovery Unit”, and provides some advices to refine the related technical standards.
\end{abstract}

\section{Overview of domestic and international vapor recovery unit and standards development}

Gasoline vapor recovery is a kind of high-tech energysaving and environmental advanced technology. The application of vapor recovery technology is to recover gasoline vapor discharged during storage, transportation and loading and unloading process that can prevent air pollutant caused by vapor volatilization and eliminate potential safety hazards. Meanwhile, the technology can also get better environmental and economic benefits with improved energy efficiency. Vapor recovery unit can be divided into units such as bulk gasoline terminals, gasoline filling stations and gasoline terminals by different application occasions; according to different recovery methods, gasoline vapor recovery technologies usually include methods such as adsorption, absorption, condensation, membrane separation and combination.

Current technical methods of gasoline vapor recovery are diverse and complex, and each of them has their own characteristics and advantages. The adsorption method utilizes the adsorption capacity of activated carbon, silica gel or reactive fiber on the oil/air mixture to achieve the separation of gasoline vapor, which can achieve higher treatment efficiency and lower emission concentration; but the activated carbon is easily deactivated, and there is a secondary pollution problem. The absorption method separates gasoline vapor and air according to difference solubility in the absorbent of each component in the vapor and oil mixture. The process is simplified, and the investment cost is low, but the disadvantages are large space occupied by the equipment, low recovery efficiency, large absorbent consumption, and more energy consumed by the system. The condensation method uses the refrigeration technology to replace the heat of the gasoline vapor, and realizes the direct conversion of the gasoline vapor components from the gas phase to the liquid phase. The process theory has some advantages such as simple, high automation level, and high safety, but the refrigeration energy consumption is high. The membrane separation method is characterized in that the special polymer membrane is preferentially permeable to hydrocarbons, so that the gasoline vapor molecules preferentially permeate the polymer membrane with air components trapped and discharged, and the enriched gasoline vapor is transported back to the oil tank or by other methods to liquefy, and this process is also relatively simple, with advanced technology and high safety grade, but the membrane separation device requires steady flow and steady-state gas. The "integrated method of gasoline vapor recovery" refers to "a method that combines two or more methods of gasoline vapor recovery such as adsorption, absorption, condensation, membrane separation".

Since the 1960s, developed countries have generally enacted various laws, regulations and vapor emission standards that open up research on vapor recovery technologies and equipment. In the late 1970s, the world's first secondary vapor recovery technology, balanced, was produced in the United States. In 1990, a vacuum-assisted secondary gasoline vapor recovery system began to

\footnotetext{
* Corresponding author: huangjin@cnis.gov.cn
} 
emerge in California. Internationally, through decades of research and practice summary, large-scale governance was carried out at the end of the last century. At present, Europe, the United States and Japan are in an international leading position in aspect of vapor recovery unit development. In China's gasoline filling stations, bulk gasoline terminals, and refineries, oil evaporation loss is a new air pollutant source control work, especially before and after the Olympics, the state has increased environmental protection efforts, giving high priority to gasoline vapor recovery. In 2007, the State Environmental Protection Administration and the General Administration of Quality Supervision, Inspection and Quarantine jointly issued three mandatory emission standards for air pollutants, including GB20950 Emission Standards of Air Pollutants for Bulk Gasoline Terminals and GB20951 Emission Standards of Air Pollutants for Gasoline Transport, and GB20952 Emission Standards of Air Pollutants for Gasoline Filling Stations stipulate emission limits and related technical points; relevant national departments have also promulgated a number of standards and norms. In 2015, the former State Environmental Protection Agency issued and implemented GB 31570 Emission Standard of Pollutants for Petroleum Refining Industry and GB31571 Emission Standard of Pollutants for Petroleum Chemistry Industry, marking that China's governance of gasoline vapor emissions has entered the stage of policy promotion and accelerating implementation.

\section{The necessity and urgency of developing general technical standards for vapor recovery unit in China}

\subsection{Supporting the implementation of relevant policy plans for volatile organic compounds in key industries}

During period from the Twelfth Five-Year Plan to the Thirteenth Five-Year Plan, new policies and plans related to air pollutants control were introduced intensively. The emission control of volatile organic compounds in the industry has been listed as the key area of China's current ecological environmental protection work. On May 24, 2013, the former Ministry of Environmental Protection's proposed in "Volatile Organic Compound Control Technology Policy" that "To strengthen the source and process control of volatile organic compounds, bulk gasoline terminals, gasoline filling stations and tank trucks should be equipped with corresponding gasoline vapor collection systems. Bulk gasoline terminals and gasoline filling stations should be equipped with corresponding vapor recovery systems." On September 12, 2013, the Action Plan for Air Pollutants Prevention and Control issued by the State Council pointed out: "We must increase comprehensive management efforts to reduce emissions of multiple pollutants. We need complete the gasoline vapor recovery and treatment of gasoline filling stations and bulk gasoline terminals tanks and tank trucks in a limited time. The crude oil and product gasoline terminals should actively perform gasoline vapor recovery management. On August 29, 2015, Article 47 of the Law of the People's Republic of China on the Prevention and Control of Air pollutants of the People's Republic of China clearly stated: "Gasoline vapor depot, refueling and gasoline filling stations, crude oil product gasoline terminals, crude oil product transport ship and tank trucks, gas tankers, etc., should install the vapor recovery unit in accordance with relevant national regulations and maintain normal usage." On July 8, 2016, the Ministry of Industry and Information Technology and the Ministry of Finance proposed in the Action Plan for Volatile Organic Compound Reduction in Key Industries "To implement process technology transformation project, petroleum refining and petrochemical industry, adopt gasoline vapor recovery system and closed collection system etc. to reduce the VOCs emissions during the storage and transportation of oils (fuels, solvents)." On December 20, 2016, Thirteenth Five-Year Plan for Energy Conservation and Emission Reduction of the State Council pointed out: "We should promote the reduction of mobile source pollutants, gasoline vapor recovery at bulk gasoline terminals and gas storage, refueling and gasoline filling stations, crude oil products terminal, and transportation process of crude oil products and gasoline vapor tankers."

In addition, important regulations such as the Thirteenth Five-Year Plan, the Thirteenth Five-Year Plan for Energy Conservation and Environmental Protection Development, and the Thirteenth Five-Year Control Plan for Volatile Organic Compounds Emissions Amount in Key Areas also raise the requirements for strict control of emissions in the petrochemical industry. In order to better support the implementation of environmental protection policies and plans in the field of gasoline vapor recovery, improve the VOC emission standard system, and support the implementation of relevant pollutant discharge standards, we should accelerate the development of relevant technical standards for China's vapor recovery unit.

\subsection{Conducive to the standardized development of technologies and equipment in the gasoline vapor recovery industry}

China's comprehensive reform of the vapor recovery system for petrochemical enterprises began in 2007. Due to the late start, the experience in the design and production of vapor recovery unit is insufficient, and the technical level of the recovery units is uneven, which also brings chaos state of domestic gasoline vapor recovery market; and currently complete technical specifications and standards for the design and manufacture of vapor recovery unit is not available internationally, so there is an urgent need to comply with current national laws and regulations, pollutant discharge standards, and related design requirements and industry specifications to study and develop national standards for vapor recovery unit. To this end, it is urgent to establish a national standard for general technical conditions of vapor recovery unit to provide a basic, unified and mandatory principles and 
requirements for vapor recovery unit, with particular emphasis on safety, efficiency, energy conservation, environmental protection and other technical requirements. It is very important to ensure the safety of vapor recovery unit, improve the performance indicators of vapor recovery unit, promote technological progress, shorten the gap with developed countries, regulate market order, enhance market competitiveness, protect the environment, save energy and reduce emissions. All of that have practical significances.

To this end, in 2011, the National Environmental Protection Industry Standardization Technical Committee (SAC/TC275) proposed the national standard "General specifications of gasoline vapor recovery unit" development project that was approved by the National Standards Committee [2011] No. 57 with a project number 20110186-Q-303. After several years of standard development, the national standard GB/T 35579 General Specifications of Gasoline Vapor Recovery Unit was officially released on January 10, 2018, and will be officially implemented on July 1, 2018.

\section{General specifications for complete sets of gasoline vapor recovery unit}

\subsection{Main content and scope of the standard}

GB/T 35579 stipulates information of vapor recovery unit such as terms and definitions, classification and naming, general principles, conditions of use, design, requirements, test methods, inspection rules, marking, packaging, transportation and storage. The design, manufacture and inspection of gasoline vapor recovery units that are to absorbe emissions from bulk gasoline terminals, gasoline filling stations and gasoline terminals could be referenced for other oil product recovery units.

\subsection{Key terms and definitions}

The standard specifies ten related terms and definitions such as gasoline vapor, vapor recovery efficiency, vapor emission concentration, vapor recovery unit, vapor recovery by adsorption method, vapor recovery by absorption method, vapor recovery by condensation method, vapor recovery by membrane method, vapor recovery by integrated methods, and processing capacity. Among them, the "vapor recovery unit" is defined as: "a vapor recovery unit (VRU) that separate gasoline vapor and air mixtures and recover gasoline vapor by methods such as adsorption, absorption, condensation, and membrane. The complete unit is mainly composed of static equipment (absorption tower, adsorption tank, membrane separator, heat exchanger, refrigeration equipment, etc.), dynamic equipment (engine, pump), piping system (pipes and accessories, pipeline flame arresters, etc.), parameter monitoring and control systems, etc.

\subsection{Technical Specifications}

In National Standard GB/T 35579, technical requirements include general content, design and performance requirements, main structural components and component requirements of various technical devices, complete sets, anti-static and electrical safety requirements, manufacturing requirements and explosion-proof requirements.

\subsubsection{General requirements}

The vapor recovery unit shall comply with national and industrial standards and technical specifications about air pollutant emissions, power, electricity, explosion-proof, fire safety, noise, etc.; its design shall be safe, stable, reliable, easy to maintain, and low energy consumption. Manufacture requirements shall comply with the drawings and technical documents approved by the specified procedures, and the performances of all aspects shall meet the requirements of this standard. All pressure tanks and pipelines shall comply with the relevant national special equipment production license requirements; motors, compressors (refrigerators), electrical and control equipment shall have explosionproof performance, and the explosion-proof grade shall not be lower than dIIBT4. The vapor emissions shall comply with the provisions of GB 20950-2007 and GB 20952-2007, and the noise emission shall comply with the provisions of GB 12348 Environmental Noise Emission Standards for Industrial Enterprises Boundary.

\subsubsection{Design requirements}

Three design requirements are proposed to ensure the safety of vapor recovery unit: Firstly, the gasoline vapor concentration design requirements should be based on the highest measured vapor concentration in the highest temperature. In the absence of measured data, the saturated vapor concentration of the medium at the highest operating temperature should be taken; it can also be estimated by reference to the measured data of vapor production concentration in similar areas, similar storage and refueling equipment. Secondly, the design requirements of the processing capacity of vapor recovery unit should be determined according to the needs of the site or the concentration and total amount of gasoline vapor discharged from the facility, and the average temperature of the highest temperature month; and the design margin should be about 1.2 times. Thirdly, it's about the structural design requirements. The overall structure should be selected according to the place of use and the actual needs of the recovery method, and should consider the rationality, compactness, airtightness and completeness of the overall structural layout; sizing design of instruments like pressure tank, system pipelines, valves, pipe fittings, automation shall comply with GB $150.1 \sim$ GB 150.4 Pressure Vessel, SH/T 3074 Steel Pressure Vessels in Petrochemical Industry, TSG R0004 Supervision Regulations on safety Technology for Stationary Pressure Vessel, SH/T 3059 Specification for Pipeline Material Design Selection in Petrochemical Industry, and SH 3005 Design Specification for 
Instrumentation Selection in Petrochemical Industry respectively.

\subsubsection{Performance requirements}

GB/T 35579 proposed several performance indicators of vapor recovery efficiency, inculding system resistance, sealing, vapor emission concentration, noise emission, etc. The specific requirements of indicators are: the vapor recovery efficiency under gasoline vapor concentration should be not less than $95 \%$; the system resistance should be no more than 5000Pa under the set processing capacity; the system air tightness of the bulk gasoline terminals and recovery unit should meet the requirements of GB 209502007, while the air tightness of gasoline filling stations vapor recovery unit system shall comply with the provisions of GB 20952-2007; the vapor emission concentration shall not exceed $25 \mathrm{~g} / \mathrm{m} 3$; the noise emission level shall not exceed $70 \mathrm{~dB}(\mathrm{~A})$.

\subsubsection{Main structural parts and component requirements for various technical units}

GB/T 35579 proposed detail requirements for the main structural components and components, the main engine pump, pipeline main accessories, monitoring and control system of vapor recovery unit used in the absorption, adsorption, condensation, and membrane separation methods.

\subsubsection{Complete set, antistatic and electrical safety requirements}

GB/T 35579 raises requirements of complete sets that are mainly related to test instrument configuration, sampling facilities, electrical connections and protective grounding, on-site calibration, anti-vibration measures, piping stiffness and ease of installation requirements. The antistatic requirements is mainly for implement of relevant national mandatory standards, including regulations about the static conductivity, surface resistance, maintenance and cleaning during operation to avoid ignition hazard caused by electrostatic charges; safety requirements include those about insulation resistance, insulation strength, grounding terminal and grounding markings, electrical continuity, enclosure and electrical control rating of the equipment.

\subsubsection{Manufacturing requirements and explosion protection requirements}

GB/T 35579 also raises specific requirements for manufacturing process of vapor recovery unit such as the appearance and structure, welding, cabinets and assembly. Explosion-proof requirements are implemented in accordance with relevant national mandatory standards. The explosion-proof performance of the unit should meet standard GB3836.1 Explosive Environment Part 1: General Requirements for Equipment, GB3836.2 Explosive Atmospheres Part 2: Equipment Protection by Flameproof Enclosures "d", GB3836.4 Explosive
Atmospheres Part 4: Equipment Protection by Intrinsic Safety "i", GB3836.9 Explosive Atmospheres Part 9: Equipment Protected by type of Protection " $m$ ", and the explosion-proof mark is ExdemibIIBT4. It also defines the explosion-proof grades of electrical equipment, field instruments, indoor electronic control system. The explosion-proof grades of different systems and places are specified; the steel pipe wiring or jacket explosion-proof hose sheath and cable used in the explosion-proof area shall be explosion-proof. It also specifies requirements for the melting point of the solder, the protective net, and the impact performance of the protective cover.

\subsection{Test method and inspection rules}

GB/T 35579 provides corresponding inspection and verification methods for vapor recovery unit technical requirements, mainly appling the national and industryrelated test method standards, especially for performance testing that must be performed according to GB 20950, GB 20952, and GB 12348 mandatory national standards. The treatment capacity test of the vapor recovery unit takes simulation method that is based on the site conditions. The inspections of vapor recovery unit include factory inspection and type inspection. The standard clarifies the corresponding requirements for inspection items, sampling and judgment.

\section{Conclusions and recommendations}

The national standard of GB/T 35579 is intended to provide a basic, unified and mandatory rules and requirements for vapor recovery unit, in line with "emphasizing key point, balancing strictness and appropriateness". The technical requirements mainly focus on the safety, efficiency, energy saving and environmental protection of the unit, which takes full consideration of the current economic and technical level of China, the state of the technology in manufacturing enterprises, the policy requirements of national product development, customer's needs and opinions and suggestions, thus reflecting the advanced nature, feasibility and operability of technical requirements. With the application of new processes and technologies in the field of gasoline vapor recovery, equipment manufacturers can determine the requirements by themselves according to specific products and characteristics on the basis of this standard in the future, which will help promote fair competition and protect the legitimate rights and interests of both parties that could help regulating the market.

At present, the national standards of industrial organic gas treatment including equipment standards, performance monitoring method standards, equipment energy efficiency standards and system facilities operation effect evaluation standards are still in a state of deficiency. The development of series national standards should be accelerated with current mature technology and equipment, and meet the goal of high-quality development of advanced technologies and equipments with energy saving, environmental protection, safety and efficiency requirements. 
Table 1 List of the detail requirements

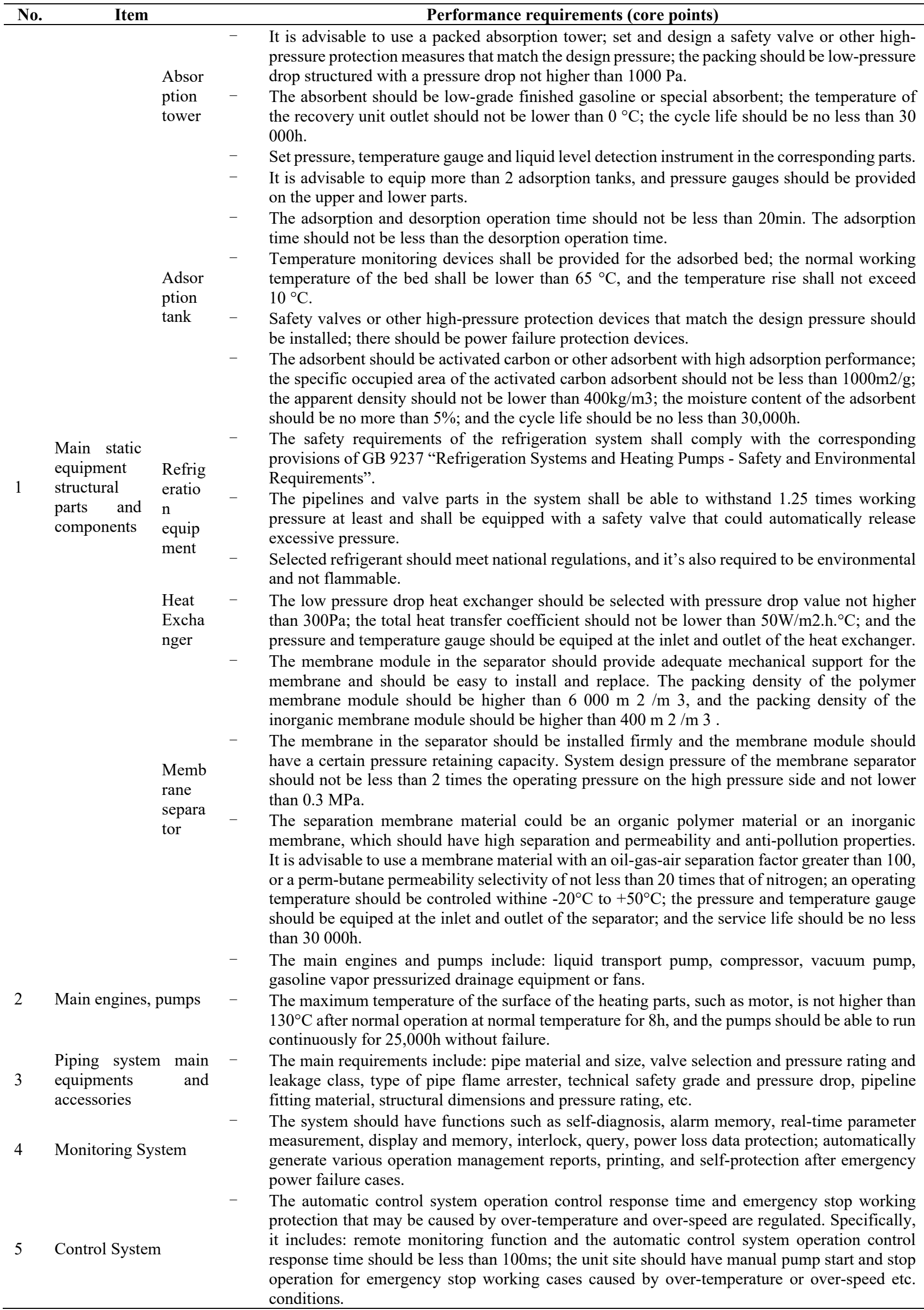


About the author: Huang Jin

Researcher of the China National Institute of Standardization, Resources and Environment Branch, member of the National Environmental Protection Industry Standardization Technical Committee (SAC/TC275) and the National Environmental Management Standardization Technical Committee (SAC/TC207). He has been engaged in the research and development of standardization scientific research and important technical standards in the fields of environmental protection industry, environmental management, and comprehensive utilization of resources. He has presided and participated in more than 20 the Eleventh Five-Year and the Twelfth Five-Year national major scientific research projects, presided over or participated in the formulation of more than 60 national standards in the fields of environmental protection industry, environmental management, and comprehensive utilization of resources.

\section{References}

1. GB 20950-2007 Emission standard of air pollutant for bulk gasoline terminals.

2. GB 20952-2007 Emission standard of air pollutant for gasoline filling stations.

3. GB 50074 Code for design of oil depot.

4. GB 50156 Code for design and construction of filling station.

5. GB 50759 Code for design of vapor recovery facilities of oil products loading system.

6. The Thirteenth Five-Year Plan for Energy Conservation and Emission Reduction of State Council, (2016).

7. The Thirteenth Five-Year Plan for Energy Conservation and Environmental Protection Industry Development issued by National Development and Reform Commission, (2016)

8. The Thirteenth Five-Year Plan, Ecological Environmental Protection Plan of State Council, (2016). 